\title{
Antiviral activity of geldanamycin and its derivatives against influenza virus
}

\author{
Thongchai Taechowisan ${ }^{1 *}$, Tipparat Samsawat ${ }^{1}$, Winyou Puckdee ${ }^{1}$, Waya S. Phutdhawong ${ }^{2}$ \\ ${ }^{1}$ Department of Microbiology, Faculty of Science, Silpakorn University, Nakhon Pathom 73000, Thailand. \\ ${ }^{2}$ Department of Chemistry, Faculty of Science, Silpakorn University, Nakhon Pathom 73000, Thailand.
}

\section{ARTICLE INFO \\ Received on: 28/10/2019 \\ Accepted on: 15/02/2020 \\ Available online: 04/04/2020}

\section{Key words:}

Antiviral activity, endophytic actinomycetes, geldanamycin, influenza virus, tryptaminegeldanamycin hybrids.

\begin{tabular}{l}
\hline ABSTRACT \\
\hline Two new geldanamycin derivatives such as 17-(tryptamine)-17-demethoxygeldanamycin (2) and \\
$17-(5$-methoxytryptamine)-17-demethoxygeldanamycin (3) were synthesized by nucleophilic substitution of the \\
$\mathrm{C} 17$ methoxyl of geldanamycin (1). Their antiviral activity was evaluated based on influenza virus propagation in \\
embryonated chicken eggs and viral absorption by hemagglutination (HA) inhibition test. The findings indicated \\
that these compounds inhibited viral propagation at a concentration of $12.5 \mu \mathrm{g} / \mathrm{ml}$. For the viral absorption, only \\
compounds $\mathbf{2}$ and $\mathbf{3}$ inhibited HA at a concentration of $50 \mu \mathrm{g} / \mathrm{ml}$. The solubility of compounds $\mathbf{2}$ and $\mathbf{3}$ in water \\
was 290 and $306 \mu \mathrm{M}$, higher than that of compound $\mathbf{1}$ about 1.91 and 2.01 times, respectively. The compounds $\mathbf{2}$ \\
and $\mathbf{3}$ showed a moderate cytotoxic activity on LLC-MK2 and Vero cells with $\mathrm{IC}_{50}$ values of $>200.00 \mu \mathrm{g} / \mathrm{ml}$. These \\
results demonstrated the invention of tryptamine-geldanamycin hybrids to prevent influenza virus infection in viral \\
absorption and viral propagation steps.
\end{tabular}

\section{INTRODUCTION}

Geldanamycin is a benzoquinone ansamycin, and it binds specifically to heat shock protein 90 (Hsp90) (Prodromou et al., 1997; Sullivan et al., 1997), resulting in dysfunction and rapid degradation of Hsp90-associated client proteins (Blagosklonny, 2002; Richter and Buckner, 2001). As a specific inhibitor of Hsp90 function, its derivatives showed antitumor activity (Miyata, 2005; Ochel et al., 2001) and has been used for the treatment of various cancers (Biamonte et al., 2010; Jhaveri et al., 2012; Pacey et al., 2006). Intervention with the Hsp90 function is the mode of action of geldanamycin (Roe et al., 1999).

For viral replications, Hsp90 is necessary for the viral protein synthesis (Burch and Weller, 2005; Basha et al., 2005; Connor et al., 2007; Geller et al., 2007; Hu and Seeger, 1996; Hu et al., 1997; Hung et al., 2002; Li et al., 2004; Smith et al., 2010; Shan et al., 2011; Waxman et al., 2001). It has been shown that

"Corresponding Author

Thongchai Taechowisan, Department of Microbiology, Faculty of Science, Silpakorn University, Nakhon Pathom 73000, Thailand.

E-mail:tewson84@hotmail.com geldanamycin blocks the replication of the viruses both in vitro and in vivo via inhibition of Hsp90 (Amraiz et al., 2017; Li et al., 2004; 2010; 2012; Luo et al., 2003; Schang et al., 2002; Smith et al., 2010; Wang et al., 2017). However, the therapeutic utilization of this compound has been restricted by low water solubility, metabolic instability, and severe hepatotoxicity (Fukuyo et al., 2009; Supko et al., 1995). Therefore, its derivatives with improved pharmacokinetic profiles have been developed. The synthesized series of geldanamycin derivatives to make new types of Hsp90 inhibitor with weak toxicity and high efficiency have been seeking (Kitson et al., 2013; Li et al., 2010; Lin et al., 2015; Modi et al., 2011; Shan et al., 2011; Supko et al., 1995; Tian et al., 2004; Wrona et al., 2010).

Tryptamine was the product of the decarboxylation of tryptophan. It has been used in the past as a vasodilator, neurotransmitter, antiviral, antibacterial, antifungal, anti-inflammatory, and antioxidant agent (Kousara et al., 2017). Its modification has been conducted to be pharmacologically active compounds. Recently, tryptamine has been synthesized as a novel non nucleosidic compound against hepatitis B virus (Qu et al., 2011). It has been a useful tool for improving the solubility, biological activities, and pharmacological properties of numerous natural 
products (Kousara et al., 2017). According to these effects, the invention of tryptamine-geldanamycin hybrids has been designed. The C17 methoxyl group of geldanamycin molecule can permit for various nucleophiles to be introduced. Thus, geldanamycin has been a popular template for producing various types of bioactive compounds (Lin et al., 2015; Modi et al., 2011; Supko et al., 1995; Tian et al., 2004; Wrona et al., 2010). Furthermore, the other report showed that some of the 17-substituted geldanamycin derivatives contained stronger activity against hepatitis B virus than geldanamycin with higher $\mathrm{LD}_{50}$ values than that of geldanamycin (Li et al., 2010). It has been reported that influenza virus replication could be inhibited by interfering the Hsp90 function (Chase et al., 2008). However, the activity of geldanamycin and its derivatives against influenza virus has been not reported. Therefore, geldanamycin could inhibit the functions of viral proteins by interfering with the complex formation of Hsp90 and viral proteins. Inhibition of Hsp90 activity also causes the inhibition of viral protein synthesis. Furthermore, it has been reported that geldanamycin could inhibit viral replication by preventing the chaperone-mediated process in viral protein folding and functions (Li et al., 2004).

In this study, novel tryptamine-geldanamycin hybrids were synthesized, their antiviral activity against influenza virus was evaluated based on virus propagation in embryonated chicken eggs and viral absorption by hemagglutination (HA) inhibition test, and their water solubility and cytotoxicity were also determined.

\section{MATERIALS AND METHODS}

\section{Isolation and cultivation of the actinomycete}

Eighteen actinomycetes were isolated from the various tissues (leaf, pseudostem, rhizome, and root) of Zingiber zerumbet (L.) Smith (Taechowisan et al., 2017). Among the 18 isolates, the isolate W14 was found to be the best producer of antibacterial substances (Taechowisan et al., 2019). This isolate was selected and identified using a polyphasic approach (Taechowisan and Lumyong, 2003; Taechowisan et al., 2019). The strain was cultured on ISP-2 agar plates at $30^{\circ} \mathrm{C}$ for 14 days and then was extracted with ethyl acetate. The crude extract was fractionated using lowto-high polar solvents (ethyl acetate in hexane) and purified on Thin Layer Chromatography (TLC) (Taechowisan et al., 2019). The purified compound was undertaken to investigate on Nuclear Magnetic Resonance (NMR) spectroscopy. The spectral data of this compound corresponded to be geldanamycin $\left(\mathrm{C}_{29} \mathrm{H}_{40} \mathrm{~N}_{2} \mathrm{O}_{9}\right)(\mathbf{1})$.

\section{Synthesis and solubility of geldanamycin derivatives}

Geldanamycin derivatives were synthesized from geldanamycin (Fig. 1) as described earlier (Taechowisan et al. 2019). The solubility of the novel geldanamycins in water was determined by comparing with geldanamycin.

\section{Viral strain propagation}

Influenza viruses $\mathrm{A}$ /free-grazing duck/Nakhon Pathom/1/2017 (H5N2) (Taechowisan et al., 2018) were cultivated in embryonated eggs. Viral titer was determined using the HA assay as previously described (Brauer and Chen, 2015).

\section{Virus cultivation inhibition assay}

Virus cultivation inhibition assay was carried out by embryonated chicken egg inoculation. About $100 \mu \mathrm{l}$ of tested compounds $(12.5,25$, and $50 \mu \mathrm{g} / \mathrm{ml})$ was incubated with 100 $\mu \mathrm{l}$ of seed virus $\left(2.86 \times 10^{8}\right.$ virus particles $\left./ \mathrm{ml}\right)$ at $37^{\circ} \mathrm{C}$ for 30 minutes, and then, $100 \mu \mathrm{l}$ of the mixture was inoculated into each embryonated chicken egg and incubated at $37^{\circ} \mathrm{C}$ for 4 days. The allantoic fluid was harvested and then was tested by HA assay (Brauer and Chen, 2015). About $20 \mu \mathrm{g} / \mathrm{ml}$ of heparin (AppliChem, Germany) was used as a positive control.

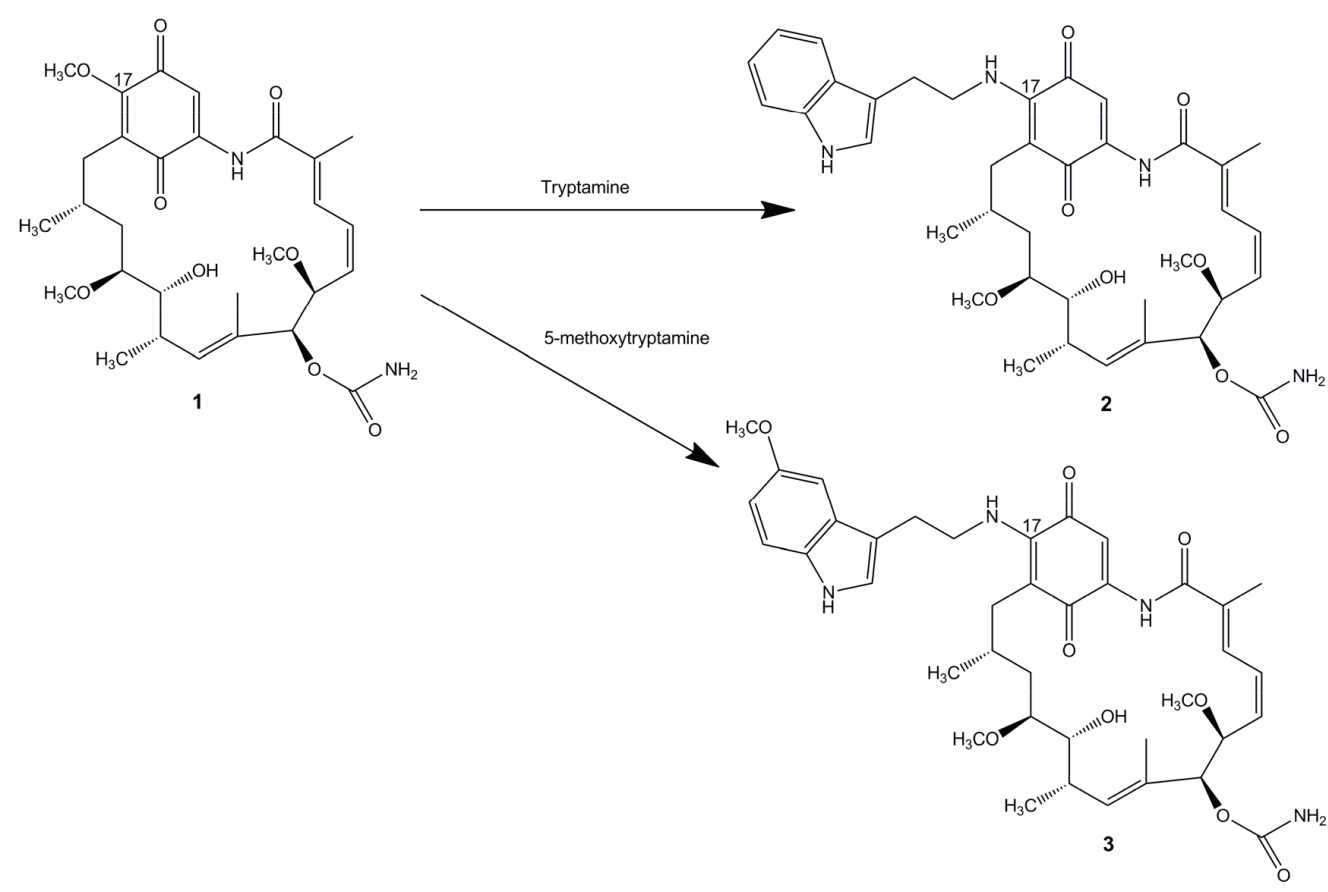

Figure 1. The semisynthetic route of 17-(tryptamine)-17-demethoxygeldanamycin (2) and 17-(5'-methoxytryptamine) -17-demethoxygeldanamycin (3) from geldanamycin (1). 


\section{HA inhibition (HAI) assay}

HAI assay was used to evaluate the effect of the compounds in virus adsorption to target cells. The compounds $(25 \mu \mathrm{l})$ with two-fold serial dilution with Phosphate Buffered Saline (PBS) were mixed with an equal volume of seed influenza virus (400 HAU per $50 \mu \mathrm{l})$. After incubation at room temperature for 30 minutes, 50 $\mu \mathrm{l}$ of the solution was mixed with an equal volume of $1 \%$ chicken erythrocyte suspension and then was incubated at $4^{\circ} \mathrm{C}$ for 30 minutes. The highest dilution of the compounds that prevented HA is called the HAI titer. About $20 \mu \mathrm{g} / \mathrm{ml}$ of heparin (AppliChem, Germany) was used as a positive control.

\section{MTT assay for cell viability}

The normal cells (LLC-MK2: rhesus monkey kidney epithelial cell line and Vero: African green monkey kidney cell line) were grown at $37^{\circ} \mathrm{C}$ in Dubecco's Modified Eagle Medium (DMEM) medium supplement with 10\% FBS, penicillin (100 units $/ \mathrm{ml})$, and streptomycin sulfate $(100 \mu \mathrm{g} / \mathrm{ml})$ in a humidified atmosphere of $5 \% \mathrm{CO}_{2}$. Cytotoxicity studies were performed on a 96-well plate. The cells were trypsinized and plated on a 96-well plate $\left(2 \times 10^{5}\right.$ per well $)$ containing DMEM medium with $10 \%$ FBS and incubated overnight. Cells were incubated with the compounds at increasing concentrations in FBS-free medium for 24 hours. Cells were washed once, and $50 \mu \mathrm{l}$ of FBS-free medium containing $5 \mathrm{mg} /$ ml 3-(4,5-dimethylthiazol-2-yl)-2,5-diphenyltetrazolium bromide (MTT) was added to each well and incubated in $5 \% \mathrm{CO}_{2}$ at $37^{\circ} \mathrm{C}$ for 4 hours. The medium was replaced with $50 \mu 1$ of DMSO to dissolve the formazan product. The optical density was measured at 450 $\mathrm{nm}$. The half inhibitory concentration $\left(\mathrm{IC}_{50}\right)$ was defined as a $50 \%$ reduction of the absorbance compared with the control assay.

\section{RESULTS}

The characterization of geldanamycins was carried out by ${ }^{1} \mathrm{H}-\mathrm{NMR},{ }^{13} \mathrm{C}-\mathrm{NMR}$, and mass spectral methods as follows.

Compound (1): The mass spectrum showed a $[\mathrm{M}+\mathrm{Na}]^{+}$ ion at $m / z 583.2571$ (molecular formula : $\mathrm{C}_{29} \mathrm{H}_{40} \mathrm{~N}_{2} \mathrm{O}_{9}$ ). The spectral data revealed this compound to be a geldanamycin, which was

Table 1. ${ }^{1} \mathrm{H}-\mathrm{NMR}$ and ${ }^{13} \mathrm{C}-\mathrm{NMR}$ spectral data of compound $\mathbf{1}$ and GDA ${ }^{\mathrm{a}}$.

\begin{tabular}{|c|c|c|c|c|c|c|c|}
\hline No. & $\delta_{\mathrm{C}}$ compound 1 & $\boldsymbol{\delta}_{\mathrm{C}}$ GDA & $\delta_{\mathrm{H}}$ compound 1 & $\delta_{\mathrm{H}}$ GDA & $\mathrm{HMBC}(\mathrm{H} \rightarrow \mathrm{C})$ & COSY & NOESY \\
\hline 1 & $169.7 \mathrm{C}$ & 169.1 & - & - & - & - & - \\
\hline 2 & $133.2 \mathrm{C}$ & 133.2 & - & - & - & - & - \\
\hline 2-Me & $12.8 \mathrm{CH}_{3}$ & 12.2 & $1.93 \mathrm{~s}$ & $1.91, \mathrm{~s}$ & $1,2,3,4$ & - & - \\
\hline 3 & $128.7 \mathrm{CH}$ & 128.4 & $6.95 \mathrm{~d}$ & $6.95, \mathrm{~d}$ & - & 4 & $\mathrm{NH}, 4,6,7$ \\
\hline 4 & $126.3 \mathrm{CH}$ & 125.7 & $6.58 \mathrm{t}$ & $6.56, \mathrm{t}$ & 2,6 & 3,5 & 3,5 \\
\hline 5 & $138.7 \mathrm{CH}$ & 137.8 & $5.81 \mathrm{br}$ & $5.80, \mathrm{t}$ & - & 4,6 & 4,6 \\
\hline 6 & $82.3 \mathrm{CH}$ & 81.6 & $4.36 \mathrm{~d}(7.6)$ & $4.34, \mathrm{~d}$ & 4, 6-OMe & 5,7 & $3,5,7$ \\
\hline 6-OMe & $57.1 \mathrm{CH}_{3}$ & 56.0 & $3.24 \mathrm{~s}$ & $3.22, \mathrm{~s}$ & 6 & - & - \\
\hline 7 & $81.1 \mathrm{CH}$ & 80.6 & $4.88 \mathrm{br}$ & 4.86 , br & $5,7-\mathrm{OCONH}_{2}, 9,8-\mathrm{Me}$ & 6 & $3,6,9$ \\
\hline 7-OCONH ${ }_{2}$ & $156.6 \mathrm{C}$ & 156.0 & - & $6.45, \mathrm{br}$ & - & - & - \\
\hline 8 & $129.1 \mathrm{C}$ & 132.6 & - & - & - & - & - \\
\hline 8-Me & $13.0 \mathrm{CH}_{3}$ & 12.5 & $1.62 \mathrm{~s}$ & $1.61, \mathrm{~s}$ & 7,9 & - & 10 \\
\hline 9 & $132.4 \mathrm{CH}$ & 131.9 & $5.50 \mathrm{~d}(8.5)$ & $5.51, \mathrm{~d}$ & 7, 8-Me & 10 & 7 \\
\hline 10 & $32.6 \mathrm{CH}$ & 32.1 & 2.56 & $3.61, \mathrm{~m}$ & - & $9,10-\mathrm{Me}$ & $8-\mathrm{Me}, 10-\mathrm{Me}, 11,12$ \\
\hline $10-\mathrm{Me}$ & $23.4 \mathrm{CH}_{3}$ & 23.3 & $0.75 \mathrm{~d}(6.8)$ & $0.97, \mathrm{~d}$ & $9,10,11$ & 10 & $10,11,12$ \\
\hline 11 & $72.4 \mathrm{CH}$ & 71.9 & $3.09 \mathrm{br}$ & $3.29, \mathrm{~s}$ & 10-Me & - & $10,10-\mathrm{Me}, 13,14$ \\
\hline $11-\mathrm{OH}$ & - & - & - & - & - & - & - \\
\hline 12 & $80.7 \mathrm{CH}$ & 80.2 & $3.09 \mathrm{br}$ & $3.07, \mathrm{~m}$ & $12-\mathrm{OMe}$ & 13 & $10,10-\mathrm{Me}, 13,14$ \\
\hline 12-OMe & $56.5 \mathrm{CH}_{3}$ & 56.6 & $3.23 \mathrm{~s}$ & $3.23, \mathrm{~s}$ & 12 & - & - \\
\hline 13 & $31.3 \mathrm{CH}_{2}$ & 31.0 & $1.45 \mathrm{br}$ & $1.45, \mathrm{~m}$ & 14-Me & 12,14 & $11,12,14$ \\
\hline 14 & $27.1 \mathrm{CH}$ & 26.6 & $1.93 \mathrm{~s}$ & $1.91, \mathrm{br}$ & 12,16 & $\begin{array}{c}13,14-\mathrm{Me} \\
15 \mathrm{a}, 15 \mathrm{~b}\end{array}$ & 13 \\
\hline 14-Me & $23.9 \mathrm{CH}_{3}$ & 23.0 & $0.97 \mathrm{br}$ & $0.76, \mathrm{~d}$ & 14,15 & 14 & - \\
\hline $15 \mathrm{a}$ & $322 \mathrm{CH}$ & 31.7 & $2.43 \mathrm{dd}(12.5,9.9)$ & $2.42, \mathrm{~m}$ & $13,14,16,17,21$ & $14,15 b$ & - \\
\hline $15 \mathrm{~b}$ & $32.2 \mathrm{CH}_{2}$ & 31.7 & $2.18 \mathrm{dd}(12.5,4.8)$ & & $13,14,16,17,21$ & $14,15 \mathrm{a}$ & - \\
\hline 16 & $128.7 \mathrm{C}$ & 128.1 & - & - & - & - & - \\
\hline 17 & $156.9 \mathrm{C}$ & 156.4 & - & - & - & - & - \\
\hline 17-OMe & $61.6 \mathrm{CH}_{3}$ & 61.0 & $3.96 \mathrm{~s}$ & $3.93, \mathrm{~s}$ & 17 & - & - \\
\hline 18 & $184.3 \mathrm{C}$ & 183.6 & - & - & - & - & - \\
\hline 19 & $111.3 \mathrm{CH}$ & 110.9 & $7.04 \mathrm{~s}$ & $7.02, \mathrm{~s}$ & - & - & - \\
\hline 20 & $140.1 \mathrm{C}$ & 139.6 & - & - & - & - & - \\
\hline 21 & $183.6 \mathrm{C}$ & 183.1 & - & - & - & - & - \\
\hline NH & - & - & $9.18, \mathrm{NH}$, br & $9.14, \mathrm{NH}, \mathrm{br}$ & $1,19,21$ & - & 3 \\
\hline
\end{tabular}

a GDA, geldanamycin (data from Ōmura et al., 1979). 
in agreement with those of geldanamycin (Table 1), previously described by Omura et al. (1979) and Qin and Panek (2008).
Compound (2): The mass spectrum showed a $[\mathrm{M}+\mathrm{Na}]^{+}$ ion at $m / z 711.3384$ (molecular formula: $\mathrm{C}_{38} \mathrm{H}_{48} \mathrm{~N}_{4} \mathrm{O}_{8}$ ). The structure

Table 2. ${ }^{1} \mathrm{H}-\mathrm{NMR}$ and ${ }^{13} \mathrm{C}-\mathrm{NMR}$ spectral data of compound $\mathbf{2}$ and compound $\mathbf{3}$.

\begin{tabular}{|c|c|c|c|c|}
\hline No. & $\delta_{\mathrm{C}}$ compound 2 & $\delta_{\mathrm{C}}$ compound 3 & $\delta_{\mathrm{H}}$ compound 2 & $\delta_{\mathrm{H}}$ compound 3 \\
\hline 1 & $168.4 \mathrm{C}$ & $168.4 \mathrm{C}$ & - & - \\
\hline 2 & $135.0 \mathrm{C}$ & $135.0 \mathrm{C}$ & - & - \\
\hline 2-Me & $12.5 \mathrm{CH}_{3}$ & $12.6 \mathrm{CH}_{3}$ & $2.02 \mathrm{~s}$ & $2.02 \mathrm{~s}$ \\
\hline 3 & $126.9 \mathrm{CH}$ & $127.0 \mathrm{CH}$ & $6.95 \mathrm{~d}(12)$ & $6.95 \mathrm{~d}(11.4)$ \\
\hline 4 & $126.5 \mathrm{CH}$ & $126.6 \mathrm{CH}$ & $6.58 \mathrm{t}(12)$ & $6.57 \mathrm{t}(11.4)$ \\
\hline 5 & $135.8 \mathrm{CH}$ & $138.7 \mathrm{CH}$ & $5.86 \mathrm{~m}$ & $5.86 \mathrm{~m}$ \\
\hline 6 & $81.2 \mathrm{CH}$ & $81.3 \mathrm{CH}$ & $4.30 \mathrm{~d}(9.9)$ & $4.31 \mathrm{~d}(9.9)$ \\
\hline 6-OMe & $57.1 \mathrm{CH}_{3}$ & $57.1 \mathrm{CH}_{3}$ & $3.26 \mathrm{~s}$ & $3.27 \mathrm{~s}$ \\
\hline 7 & $81.7 \mathrm{CH}$ & $81.1 \mathrm{CH}$ & $5.18 \mathrm{~s}$ & $5.18 \mathrm{~s}$ \\
\hline 7-OCONH & $156.1 \mathrm{C}$ & $156.1 \mathrm{C}$ & - & - \\
\hline 8 & $132.7 \mathrm{C}$ & $132.8 \mathrm{C}$ & - & - \\
\hline 8-Me & $12.7 \mathrm{CH}_{3}$ & $12.8 \mathrm{CH}_{3}$ & $1.80 \mathrm{~s}$ & $1.80 \mathrm{~s}$ \\
\hline 9 & $133.8 \mathrm{CH}$ & $133.8 \mathrm{CH}$ & $5.89 \mathrm{~m}$ & 5.89 \\
\hline 10 & $32.3 \mathrm{CH}$ & $32.4 \mathrm{CH}$ & $2.74 \mathrm{~m}$ & $2.74 \mathrm{~m}$ \\
\hline 10-Me & $12.3 \mathrm{CH}_{3}$ & $12.4 \mathrm{CH}_{3}$ & $0.99 \mathrm{~d}(6.9)$ & $1.00 \mathrm{~d}(6.9)$ \\
\hline 11 & $72.6 \mathrm{CH}$ & $72.7 \mathrm{CH}$ & $3.57 \mathrm{~d}(9)$ & $3.57 \mathrm{~m}$ \\
\hline $11-\mathrm{OH}$ & - & - & - & - \\
\hline 12 & $81.5 \mathrm{CH}$ & $81.6 \mathrm{CH}$ & $3.45 \mathrm{~m}$ & $3.45 \mathrm{~m}$ \\
\hline 12-OMe & $56.7 \mathrm{OCH}_{3}$ & $56.7 \mathrm{OCH}_{3}$ & $3.36 \mathrm{~s}$ & $3.36 \mathrm{~s}$ \\
\hline 13 & $35.0 \mathrm{CH}_{2}$ & $35.2 \mathrm{CH}_{2}$ & $1.77 \mathrm{~m}$ & $1.77 \mathrm{~m}$ \\
\hline 14 & $28.5 \mathrm{CH}$ & $28.6 \mathrm{CH}$ & $1.77 \mathrm{~m}$ & $1.77 \mathrm{~m}$ \\
\hline 14-Me & $22.8 \mathrm{CH}_{3}$ & $23.0 \mathrm{CH}_{3}$ & $0.93 \mathrm{~d}(6.3)$ & $0.94 \mathrm{~d}(6.3)$ \\
\hline $15 \mathrm{a}$ & \multirow{2}{*}{$34.4 \mathrm{CH}_{2}$} & \multirow{2}{*}{$34.5 \mathrm{CH}_{2}$} & 2.70 & $2.68 \mathrm{~m}(12.5,9.9)$ \\
\hline $15 \mathrm{~b}$ & & & 2.40 & $2.44 \mathrm{~m}(12.5,4.8)$ \\
\hline 16 & $108.6 \mathrm{C}$ & $108.5 \mathrm{C}$ & - & - \\
\hline 17 & $144.9 \mathrm{C}$ & $145.0 \mathrm{C}$ & - & - \\
\hline 17-OMe & - & - & - & - \\
\hline 18 & $183.8 \mathrm{C}$ & $183.9 \mathrm{C}$ & - & - \\
\hline 19 & $108.7 \mathrm{CH}$ & $108.7 \mathrm{CH}$ & $7.24 \mathrm{~s}$ & $7.24 \mathrm{~s}$ \\
\hline 20 & $141.4 \mathrm{C}$ & $141.4 \mathrm{C}$ & - & - \\
\hline 21 & $180.5 \mathrm{C}$ & $180.6 \mathrm{C}$ & - & - \\
\hline $22 \mathrm{a}$ & \multirow{2}{*}{$45.7 \mathrm{CH}_{2}$} & \multirow{2}{*}{$45.6 \mathrm{CH}_{2}$} & $3.91 \mathrm{~m}$ & $3.92 \mathrm{~m}$ \\
\hline $22 b$ & & & $3.77 \mathrm{~m}$ & $3.76 \mathrm{~m}$ \\
\hline 23 & $25.75 \mathrm{CH}_{2}$ & $25.8 \mathrm{CH}_{2}$ & $3.15 \mathrm{t}(6.6)$ & $3.11 \mathrm{t}(6.6)$ \\
\hline 24 & $111.3 \mathrm{C}$ & $111.0 \mathrm{C}$ & - & - \\
\hline 25 & $122.5 \mathrm{CH}$ & $123.4 \mathrm{CH}$ & $7.13 \mathrm{~m}$ & 7.09 \\
\hline 26 & $136.6 \mathrm{C}$ & $131.8 \mathrm{C}$ & - & - \\
\hline 27 & $126.8 \mathrm{C}$ & $127.3 \mathrm{C}$ & - & - \\
\hline 28 & $111.5 \mathrm{CH}$ & $100.4 \mathrm{CH}$ & $7.40 \mathrm{~d}(7.8)$ & $7.00 \mathrm{~s}$ \\
\hline 29 & $119.8 \mathrm{CH}$ & $154.3 \mathrm{C}$ & $7.13 \mathrm{~m}$ & - \\
\hline 29-OMe & - & $56.0 \mathrm{OCH}_{3}$ & - & $3.87 \mathrm{~s}$ \\
\hline 30 & $125.6 \mathrm{CH}$ & $112.3 \mathrm{CH}$ & $7.15 \mathrm{~m}$ & $7.29 \mathrm{~d}(9)$ \\
\hline 31 & $118.5 \mathrm{CH}$ & $112.7 \mathrm{CH}$ & $7.60 \mathrm{~d}(7.8)$ & $6.90 \mathrm{~d}(9)$ \\
\hline $1-\mathrm{NH}$ & - & - & $9.17 \mathrm{~s}$ & $9.17 \mathrm{~s}$ \\
\hline 22-NH & - & - & 6.47 brs $(6.0)$ & $6.47 \mathrm{t}(6.0)$ \\
\hline $25-\mathrm{NH}$ & - & - & $8.25 \mathrm{~s}$ & $8.14 \mathrm{~s}$ \\
\hline
\end{tabular}


was fully elucidated by ${ }^{1} \mathrm{H}-\mathrm{NMR},{ }^{13} \mathrm{C}$-NMR spectroscopy, DEPT135, and 2D-NMR spectral data (Table 2).

Compound (3): The mass spectrum showed a $[\mathrm{M}+\mathrm{Na}]^{+}$ ion at $\mathrm{m} / \mathrm{z} 741.3482$ (molecular formula : $\mathrm{C}_{39} \mathrm{H}_{50} \mathrm{~N}_{4} \mathrm{O}_{9}$ ). The structure was fully elucidated by ${ }^{1} \mathrm{H}-\mathrm{NMR},{ }^{13} \mathrm{C}-\mathrm{NMR}$ spectroscopy, DEPT-135, and 2D-NMR spectral data (Table 2), and the spectral data of this compound were compared with the spectral data of compound 1 (Table 3).

Table 3. ${ }^{1} \mathrm{H}-\mathrm{NMR}$ and ${ }^{13} \mathrm{C}-\mathrm{NMR}$ spectral data of compound $\mathbf{3}$ and compound $\mathbf{1}$.

\begin{tabular}{|c|c|c|c|c|c|c|}
\hline No. & $\delta_{\mathrm{C}}$ compound 3 & $\delta_{\mathrm{C}}$ compound 1 & $\delta_{\mathrm{H}}$ compound 3 & $\delta_{\mathrm{H}}$ compound 1 & HMBC $(\mathrm{H} \rightarrow \mathrm{C})$ & COSY \\
\hline 1 & $168.4 \mathrm{C}$ & $169.7 \mathrm{C}$ & - & - & - & - \\
\hline 2 & $135.0 \mathrm{C}$ & $133.2 \mathrm{C}$ & - & - & - & - \\
\hline 2-Me & $12.6 \mathrm{CH}_{3}$ & $12.8 \mathrm{CH}_{3}$ & $2.02 \mathrm{~s}$ & $1.93 \mathrm{~s}$ & $1,2,3$ & - \\
\hline 3 & $127.0 \mathrm{CH}$ & $128.7 \mathrm{CH}$ & $6.95 \mathrm{~d}(11.4)$ & $6.95 \mathrm{~d}$ & $1,2,2-\mathrm{Me}, 4,5$ & 4 \\
\hline 4 & $126.6 \mathrm{CH}$ & $126.3 \mathrm{CH}$ & $6.57 \mathrm{t}(11.4)$ & $6.58 \mathrm{t}$ & $2,3,5$ & 3,5 \\
\hline 5 & $135.8 \mathrm{CH}$ & $138.7 \mathrm{CH}$ & $5.86 \mathrm{~m}$ & 5.81 brs & $3,4,6,7$ & 4,6 \\
\hline 6 & $81.3 \mathrm{CH}$ & $82.3 \mathrm{CH}$ & $4.31 \mathrm{~d}(9.9)$ & $4.36 \mathrm{~d}(7.6)$ & 4, 6-OMe & 5,7 \\
\hline 6-OMe & $57.1 \mathrm{CH}_{3}$ & $57.1 \mathrm{CH}_{3}$ & $3.27 \mathrm{~s}$ & $3.24 \mathrm{~s}$ & 6 & - \\
\hline 7 & $81.8 \mathrm{CH}$ & $81.1 \mathrm{CH}$ & $5.18 \mathrm{~s}$ & $4.88 \mathrm{brs}$ & 5, 7--OCONH $4,8,8-\mathrm{Me}, 9$ & 6 \\
\hline 7-OCONH & $156.1 \mathrm{C}$ & $156.6 \mathrm{C}$ & - & - & - & - \\
\hline 8 & $132.8 \mathrm{C}$ & $129.1 \mathrm{C}$ & - & - & - & - \\
\hline 8-Me & $12.8 \mathrm{CH}_{3}$ & $13.0 \mathrm{CH}_{3}$ & $1.80 \mathrm{~s}$ & $1.62 \mathrm{~s}$ & $7,8,9$ & - \\
\hline 9 & $133.8 \mathrm{CH}$ & $132.4 \mathrm{CH}$ & $5.89 *$ & $5.50 \mathrm{~d}(8.5)$ & 7, 8-Me, 10-Me, 11 & 10 \\
\hline 10 & $32.4 \mathrm{CH}$ & $32.6 \mathrm{CH}$ & $2.74 \mathrm{~m}$ & 2.56 & $8,9,10-\mathrm{Me}$ & $9,10-\mathrm{Me}, 11$ \\
\hline 10-Me & $12.4 \mathrm{CH}_{3}$ & $13.4 \mathrm{CH}_{3}$ & $1.00 \mathrm{~d}(6.9)$ & $0.75 \mathrm{~d}(6.8)$ & $9,10,11$ & 10 \\
\hline 11 & $72.7 \mathrm{CH}$ & $72.4 \mathrm{CH}$ & $3.57 \mathrm{~m}$ & 3.09 brs & $9,10,10-\mathrm{Me}, 12$ & 10,12 \\
\hline $11-\mathrm{OH}$ & - & - & - & - & - & - \\
\hline 12 & $81.6 \mathrm{CH}$ & $80.7 \mathrm{CH}$ & $3.45 \mathrm{~m}$ & 3.09 brs & $10,11,12-\mathrm{OMe}, 14$ & 11,13 \\
\hline 12-OMe & $56.7 \mathrm{OCH}_{3}$ & $56.5 \mathrm{CH}_{3}$ & $3.36 \mathrm{~s}$ & $3.23 \mathrm{~s}$ & 12 & - \\
\hline 13 & $35.2 \mathrm{CH}_{2}$ & $31.3 \mathrm{CH}_{2}$ & $1.77 \mathrm{~m}$ & 1.45 brs & $11,12,14$ & 12 \\
\hline 14 & $28.6 \mathrm{CH}$ & $27.1 \mathrm{CH}$ & $1.77 \mathrm{~m}$ & $1.93 \mathrm{~s}$ & 12,13 & $14-\mathrm{Me}, 15 \mathrm{~b}$ \\
\hline 14-Me & $23.0 \mathrm{CH}_{3}$ & $23.9 \mathrm{CH}_{3}$ & $0.94 \mathrm{~d}(6.3)$ & 0.97 brs & $13,14,15$ & 14 \\
\hline $15 \mathrm{a}$ & $345 \mathrm{CH}$ & $322 \mathrm{CH}$ & $2.68 \mathrm{~m}$ & $2.43 \mathrm{dd}(12.5,9.9)$ & $13,14,14-\mathrm{Me}, 16,17,21$ & $15 b$ \\
\hline $15 b$ & $34.5 \mathrm{CH}_{2}$ & $32.2 \mathrm{CH}_{2}$ & $2.44 \mathrm{~m}$ & $2.18 \mathrm{dd}(12.5,4.8)$ & $14,16,17,21$ & $14,15 \mathrm{a}$ \\
\hline 16 & $108.5 \mathrm{C}$ & $128.7 \mathrm{C}$ & - & - & - & - \\
\hline 17 & $145.0 \mathrm{C}$ & $156.9 \mathrm{C}$ & - & - & - & - \\
\hline 17-OMe & - & $61.6 \mathrm{CH}_{3}$ & - & $3.96 \mathrm{~s}$ & - & - \\
\hline 18 & $183.9 \mathrm{C}$ & $184.3 \mathrm{C}$ & - & - & - & - \\
\hline 19 & $108.7 \mathrm{CH}$ & $111.3 \mathrm{CH}$ & $7.24 \mathrm{~s}$ & $7.04 \mathrm{~s}$ & 17,21 & - \\
\hline 20 & $141.4 \mathrm{C}$ & $140.1 \mathrm{C}$ & - & - & - & - \\
\hline 21 & $180.6 \mathrm{C}$ & $183.6 \mathrm{C}$ & - & - & - & - \\
\hline $22 \mathrm{a}$ & CEU & & $3.92 \mathrm{~m}$ & - & 23,24 & $22 \mathrm{~b}, 22-\mathrm{NH}, 23$ \\
\hline $22 b$ & $45.6 \mathrm{CH}_{2}$ & - & $3.76 \mathrm{~m}$ & - & 23,24 & 22a, 22-NH, 23 \\
\hline 23 & $25.8 \mathrm{CH}_{2}$ & - & $3.11 \mathrm{t}(6.6)$ & - & $22,24,25$ & $22 \mathrm{a}, 22 \mathrm{~b}$ \\
\hline 24 & $111.0 \mathrm{C}$ & - & - & - & - & - \\
\hline 25 & $123.4 \mathrm{CH}$ & - & $7.09 *$ & - & $23,24,26,27$ & - \\
\hline 26 & $131.8 \mathrm{C}$ & - & - & - & - & - \\
\hline 27 & $127.3 \mathrm{C}$ & - & - & - & - & - \\
\hline 28 & $100.4 \mathrm{CH}$ & - & $7.00 \mathrm{~s}$ & - & $24,26,29,30$ & - \\
\hline 29 & $154.3 \mathrm{C}$ & - & - & - & - & - \\
\hline 29-OMe & $56.0 \mathrm{OCH}_{3}$ & - & $3.87 \mathrm{~s}$ & - & 29 & - \\
\hline 30 & $112.3 \mathrm{CH}$ & - & $7.29 \mathrm{~d}(9)$ & - & 29 & 31 \\
\hline 31 & $112.7 \mathrm{CH}$ & - & $6.90 \mathrm{~d}(9)$ & - & $26,27,29$ & 30 \\
\hline $1-\mathrm{NH}$ & - & - & $9.17 \mathrm{~s}$ & $9.18, \mathrm{NH}$, brs & $1,19,21$ & - \\
\hline $22-\mathrm{NH}$ & - & - & $6.47 \mathrm{t}(6.0)$ & - & $16,18,22,23$ & $22 a, 22 b$ \\
\hline $25-\mathrm{NH}$ & - & - & $8.14 \mathrm{~s}$ & - & $24,25,26,27$ & 25 \\
\hline
\end{tabular}


The water solubility of geldanamycin (1) was found to be $151.60 \mu \mathrm{M}$ (Table 4). In contrast, the solubility of its derivatives (2 and 3) in water was 290 and $306 \mu \mathrm{M}$, respectively, about 1.91 and 2.01 times higher than that of geldanamycin, respectively. These data suggest that the conjugation of a tryptamine moiety to geldanamycin at the $\mathrm{C} 17$ position greatly enhanced their water solubility.

The effect of geldanamycin and its derivatives on influenza virus propagation was evaluated at various concentrations in embryonated chicken eggs. The virus yields were determined by HA test. The virus propagation was obtained only in control, whereas no virus was detected in the compound treatments. In addition, the effect of geldanamycin and its derivatives on viral adsorption to chicken erythrocytes was carried out. Interestingly, as expected, the compounds 2 and 3 inhibited viral binding to the cells with HAI titer of 1:50, whereas geldanamycin could not inhibit viral binding to the cells (Table 4). These data suggested that geldanamycin and its derivatives inhibited influenza virus propagation, but tryptaminegeldanamycin hybrids could inhibit the viral adsorption (early step) of influenza virus infection. Heparin at the concentration of $20 \mu \mathrm{g} / \mathrm{ml}$ could completely inhibit both viral propagation and viral absorption (data not shown).

Geldanamycin and its derivatives were evaluated for cytotoxicity activity against LLC-MK2 and Vero cell lines using the MTT assay. The compounds $\mathbf{2}$ and $\mathbf{3}$ exhibited weak cytotoxicity activity toward LLC-MK2 and Vero cells with $\mathrm{IC}_{50}$ values of $>200.00 \mu \mathrm{g} / \mathrm{ml}$ (Table 5). The results show that two novel geldanamycin possesses low toxicity to normal cells and can display potential application in antiviral chemoprevention and chemotherapy.

\section{DISCUSSION}

Influenza virus causes seasonal outbreaks in temperate regions, with an increase in disease and mortality rate which is a serious problem. With the expectation of exploiting the potency of Hsp90 inhibitor against influenza virus, we investigated an in vitro inhibitory activity of geldanamycin and its derivatives against influenza virus as they were promising candidates in vitro.

Table 4. Water solubility and HAI titers of geldanamycins.

\begin{tabular}{cccccc}
\hline Compounds & MW & $\begin{array}{c}\text { Solubility } \\
\text { in water } \\
(\mathbf{m g} / \mathbf{m l})\end{array}$ & $\begin{array}{c}\text { Solubility } \\
\text { in water } \\
(\boldsymbol{\mu M})\end{array}$ & $\begin{array}{c}\text { Relative } \\
\text { solubility }\end{array}$ & $\begin{array}{c}\text { Hemagglutination } \\
\text { inhibition titers }\end{array}$ \\
\hline 1 & 560 & 0.085 & 151.60 & 1.00 & $\mathrm{ND}^{\mathrm{a}}$ \\
2 & 688 & 0.200 & 290 & 1.90 & $1: 50$ \\
3 & 718 & 0.250 & 306 & 2.00 & $1: 50$ \\
\hline
\end{tabular}

${ }^{\mathrm{a} N D}$; not determined.

Table 5. Cytotoxicity activity $\left(\mathrm{IC}_{50}\right)$ of geldanamycins.

\begin{tabular}{ccc}
\hline \multirow{2}{*}{ Compounds } & \multicolumn{2}{c}{$\mathbf{I C}_{\text {so }}{ }^{a}(\mu \mathrm{g} / \mathrm{ml})$} \\
\cline { 2 - 3 } & LLC-MK2 $^{\mathrm{b}}$ & Vero \\
\hline 1 & 73.67 & 54.25 \\
2 & $>200.00$ & $>200.00$ \\
3 & $>200.00$ & $>200.00$ \\
\hline
\end{tabular}

${ }^{\mathrm{a}} \mathrm{IC}_{50}$ values represent the concentration causing 50\% growth inhibition.

'LLC-MK2; rhesus monkey kidney epithelial cell lines, Vero; African green monkey kidney cell lines.
The toxicity and water solubility of geldanamycin have been a marked hindrance for its development for chemotherapy use. These have incentive scientists to pay attention to develop less toxic geldanamycin derivatives. In this study, compounds 2 and $\mathbf{3}$ also exhibited less cytotoxicity than geldanamycin in the normal cell lines. We also found that these compounds showed a greater increase in water solubility. It should be mentioned that the antiviral activity of geldanamycin and its derivatives appeared in influenza virus propagation, which suggests that geldanamycin and its derivatives are an option choice in terms of antiviral agents in the viral propagation step. The introduction of a tryptamine or 5 '-methoxytryptamine group at the C17-position of geldanamycin could not interfere with the binding of geldanamycin derivatives to Hsp90, but it had a largely decreased toxicity and increased water solubility. As stated by the crystal structure of the geldanamycinHsp90 complex (Stebbins et al., 1997), the substitution in the C17 methoxyl of geldanamycin is revealed to the external cavity of the Hsp90 protein, while the difference of substituents of geldanamycin is crucial for the interaction with the Hsp90 protein. According to the report by Li et al. (2010), 17-amino-17-demethoxygeldanamycin derivatives have a great potential for antiviral activity, whereas the 19-substituted geldanamycin modification was not a possibility in terms of antiviral agents. Due to the introduction of a group, the C19-position of geldanamycin could interfere with the binding of geldanamycin derivatives to Hsp90 by the steric effects ( $\mathrm{Li}$ et al., 2010). These results led us to contemplate that Hsp90 could be a target for antiviral infection and that geldanamycin and its derivatives have a great potential for antiviral propagation by interfering with Hsp90 in the protein folding and stabilizing of virus-infected cells.

The invention of tryptamine-geldanamycin hybrids has been designed at the C17-position of geldanamycin by nucleophilic substitution reactions. These compounds inhibited not only on viral propagation but also on viral absorption. It suggested that tryptamine-geldanamycin hybrids could protect viral infection in both the steps. According to this effect, Sun et al. (2019) reported that tryptophan dendrimers could block receptor binding of enterovirus A71, and these compounds could prevent binding and internalization of the virus. Furthermore, the Chinese Academy of Science, Shanghai, has shown that tryptamine derivatives had an antiviral activity against hepatitis B virus (Qu et al., 2017). This study discovered the effects of the tryptamine-geldanamycins on inhibition of influenza virus propagation and adsorption. This study will help the researcher to uncover the structural modifications of the compounds to improve biological activities.

\section{CONCLUSION}

In summary, the antiviral activity, low toxicity, and enhanced water solubility of two new tryptamine-geldanamycins, compounds $\mathbf{2}$ and $\mathbf{3}$, were presented in this work, in comparison with geldanamycin. In particular, all of these compounds showed antiviral activity in viral propagation, whereas the tryptamine-geldanamycins not only inhibit viral propagation but also inhibit viral absorption which has low toxicity and good water solubility better than geldanamycin. These results show that the functions of Hsp90 can be inhibited by these compounds and the virus cannot be propagated. This suggests a new antiviral approach. Therefore, Hsp90 could be an excellent antiviral target, and the tryptamine-geldanamycins could be considered as a new choice for antiviral agents. 


\section{ACKNOWLEDGMENTS}

The authors are grateful to Ms. Chanjira Jaramornburapong and Ms. Chanakan Winyakul in the Department of Chemistry, Faculty of Science, Silpakorn University, Thailand, for measuring NMR and Mass Spectrometry (MS) data, respectively. This work was supported by the Faculty of Science, Silpakorn University, Nakhon Pathom, Thailand.

\section{REFERENCES}

Amraiz D, Zaidi NSS, Fatima M. Antiviral evaluation of an Hsp90 inhibitor, gedunin, against dengue virus. Trop J Pharm Res, 2017; 16:997-1004.

Basha W, Kitagawa R, Uhara M, Imazu H, Uechi K, Tanaka J. Geldanamycin, a potent and specific inhibitor of Hsp90, inhibit gene expression and replication of human cytomegalovirus. Antivir Chem Chemother, 2005; 16:135-46.

Biamonte MA, Van de Water R, Arndt JW, Scannevin RH, Perret D, Lee WC. Heat shock protein 90: inhibitors in clinical trials. J Med Chem, 2010; 53:3-17.

Blagosklonny MV. Hsp-90-associated oncoproteins: multiple targets for geldanamycin and its analogs. Leukemia, 2002; 16:455-62.

Brauer R, Chen P. Influenza virus propagation in embryonated chicken eggs. J Visualized Exp, 2015; 97:e52421; doi:10.3791/52421

Burch AD, Weller SK. Herpes simplex virus type 1 DNA polymerase requires the mammalian chaperone hsp 90 for proper localization to the nucleus. J Virol, 2005; 79:10740-49.

Chase G, Deng T, Fodor E. HSP90 inhibitors reduce influenza virus replication in cell culture. Virology, 2008; 377:431-9.

Connor JH, McKenzie MO, Parks GD, Lyles DS. Antiviral activity and RNA polymerase degradation following Hsp90 inhibition in a range of negative strand viruses. Virology, 2007; 362:109-19.

Fukuyo Y, Hunt CR, Horikoshi N. Geldanamycin and its anti-cancer activities. Cancer Lett, 2009; 290:24-35.

Geller R, Vignuzzi M, Andino R, Frydman J. Evolutionary constraints on chaperone-mediated folding provide an antiviral approach refractory to development of drug resistance. Gen Dev, 2007; 21:195-205.

$\mathrm{Hu}$ J, Seeger C. Hsp90 is required for the activity of a hepatitis B virus reverse transcriptase. Proc Natl Acad Sci USA, 1996; 93:1060-4.

Hu J, Toft DO, Seeger C. Hepadnavirus assembly and reverse transcription require a multi-component chaperone complex which is incorporated into nucleocapsids. EMBO J, 1997; 16:59-68.

Hung JJ, Chung CS, Chang W. Molecular chaperone Hsp90 is important for vaccinia virus growth in cells. J Virol, 2002; 76:1379-90.

Jhaveri K, Taldone T, Modi S, Chiosis G. Advances in the clinical development of heat shock protein 90 (Hsp90) inhibitors in cancers. Biochim Biophys Acta, 2012; 1823:742-55.

Kitson RR, Chang CH, Xiong R, Williams HE, Davis AL, Lewis W, Dehn DL, Siegel D, Roe SM, Prodromou C, Ross D. Synthesis of 19-substituted geldanamycins with altered conformations and their binding to heat shock protein hsp90. Nat Chem, 2013; 5:307-14.

Kousara S, Anjuma SN, Jaleela F, Khana J, Naseema S. Biomedical significance of tryptamine: a review. J Pharmacovigil, 2017; 5:239.

Li YH, Lu QN, Wang HQ, Tao PZ, Jiang JD. Geldanamycin, a ligand of heat shock protein 90, inhibits herpes simplex virus type 2 replication both in vitro and in vivo. J Antibiot, 2012; 65:509-12.

Li YH, Tao PZ, Liu YZ, Jiang JD. Geldanamycin, a ligand of heat shock protein 90, inhibits the replication herpes simplex virus type 1 in vitro. Antimicrob Agents Chemother, 2004; 48:867-72.

Li YP, Shan GZ, Peng ZG, Zhu JH, Meng S, Zhang T, Gao LY, Tao PZ, Gao RM, Li YH, Jiang JD, Li ZR. Synthesis and biological evaluation of heat-shock protein 90 inhibitors: geldanamycin derivatives with broad antiviral activities. Antivir Chem Chemother, 2010; 20:259-68.

Lin Z, Peng R, Li Z, Wang Y, Lu C, Shen Y, Wang J, Shi G. 17-ABAG, a Novel geldanamycin derivative, inhibits LNCaP-cell proliferation through heat shock protein 90 inhibition. Int J Mol Med, 2015; $36: 424-32$.

Luo H, Zhang J, Dastvan F, Yanagawa B, Reidy MA, Zhang HM, Yang D, Wilson JE, McManus BM. Ubiquitin-dependent proteolysis of cyclin D1 is associated with coxsackievirus-induced cell growth arrest. J Virol, 2003; 77:1-9.

Miyata Y. Hsp90 inhibitor geldanamycin and its derivatives as novel cancer chemotherapeutic agents. Curr Pharm Des, 2005; 11 $1131-8$

Modi S, Stopeck A, Linden H, Solit D, Chandarlapaty S, Rosen N, D'Andrea G, Dickler M, Moynahan ME, Sugarman S, Ma W. HSP90 inhibition is effective in breast cancer: a phase II trial of tanespimycin (17-AAG) plus trastuzumab in patients with HER2-positive metastatic breast cancer progressing on trastuzumab. Clin Cancer Res, 2011; 17:5132-9.

Ochel HJ, Eichhorn K, Gademann G. Geldanamycin: the prototype of a class of antitumor drugs targeting the heat shock protein 90 family of molecular chaperones. Cell Stress Chaperones, 2001; 6:105-12.

Ōmura S, Nakagawa A, Sadakane N. Structure of herbimycin a new ansamycin antibiotic. Tetrahedron Lett, 1979; 20:4323-6.

Pacey S, Banerji U, Judson I, Workman P. Hsp90 inhibitors in the clinic. Handb Exp Pharmacol, 2006; 172:331-58

Prodromou C, Roe SM, O'Brien R, Ladbury JE, Piper PW, Pearl LH. Identification and structural characterization of the ATP/ADP-binding site in the Hsp90 molecular chaperone. Cell, 1997; 90:65-75.

Qin HL, Panek JS. Total synthesis of the Hsp90 inhibitor geldanamycin. Organic Lett, 2008; 10:2477-9.

Qu SJ, Wang GF, Duan WH, Yao SY, Zuo JP, Tan CH, Zhu DY. Tryptamine derivatives as novel non-nucleosidic inhibitors against hepatitis B virus. Bioorg Med Chem, 2011; 19:3120-7.

Richter K, Buckner J. Hsp90: chaperoning signal transduction. J Cell Physiol, 2001; 188:281-90.

Roe SM, Prodromou C, O'Brien R, Ladbury JE, Piper PW, Pearl LH. Structural basis for inhibition of the Hsp90 molecular chaperone by the antitumor antibiotics radicicol and geldanamycin. J Med Chem, 1999; $42: 260-6$.

Schang LM, Bantly A, Knockaert M, Shaheen F, Meijer L, Malim MH, Gray NS, Schaffer PA. Pharmacological cyclin-dependent kinase inhibitors inhibit replication of wild-type and drug-resistant strains of herpes simplex virus and HIV-1 by targeting cellular, not viral, proteins. J Virol, 2002; 76:7874-82.

Shan GZ, Peng ZG, Li YH, Li D, Li YP, Meng S, Gao LY, Jiang JD, Li ZR. A novel class of geldanamycin derivatives as $\mathrm{HCV}$ replication inhibitors targeting on Hsp90: synthesis, structure-activity relationships and anti-HCV activity in GS4.3 replicon cells. J Antibiot, 2011; 64:177-82.

Smith DR, McCarthy S, Chrovian A, Olinger G, Stossel A, Geisbert TW, Hensley LE, Connor JH. Inhibition of heatshock protein 90 reduces Ebola virus replication. Antiviral Res, 2010; 87:187-94.

Stebbins CE, Russo AA, Schneider C, Rosen N, Hartl FL, Pavletich NP. Crystal structure of an HSP90-geldanamycin complex: targeting of a protein chaperone by an antitumor agent. Cell, 1997; 89: $239-50$.

Sullivan W, Stensgard B, Caucutt G, Bartha B, McMahon N, Alnemri ES, Litwack G, Toft D. Nucleotides and two functional states of hsp90. J Biol Chem, 1997; 272:8007-12.

Sun L, Lee H, Thibaut HJ, Lanko K, Rivero-Buceta E, Bator C, Martinez-Gualda B, Dallmeier K, Delang L, Leyssen P, Gago F. Viral engagement with host receptors blocked by a novel class of tryptophan dendrimers that targets the 5-fold-axis of the enterovirus-A71 capsid. PLoS Pathog, 2019; 15:e1007760.

Supko JG, Hickman RL, Grever MR, Malspeis L. Preclinical pharmacologic evaluation of geldanamycin as an antitumor agent. Cancer Chemother Pharmacol, 1995; 36:305-15.

Taechowisan T, Chaisaeng S, Phutdhawong WS. Antibacterial, antioxidant and anticancer activities of biphenyls from Streptomyces sp. BO-07; an endophyte in Boesenbergia rotunda (L.) Mansf A. Food Agri Immunol, 2017; 28:1330-46. 
Taechowisan T, Dumpin K, Phutdhawong WS. Isolation of avian influenza a $(\mathrm{H} 5 \mathrm{~N} 2)$ from free-grazing ducks in Thailand and antiviral effects of tea extracts on viral propagation. Asian J Poult Sci, $2018 ; 12: 7-13$

Taechowisan T, Puckdee W, Phutdhawong WS. Streptomyces zerumbet, a Novel species from Zingiber zerumbet (L.) Smith and isolation of its bioactive compounds. Adv Microbiol, 2019; 9:194-219.

Taechowisan T, Lumyong S. Activity of endophytic actinomycetes from roots of Zingiber officinale and Alpinia galanga against phytopathogenic fungi. Ann Microbiol, 2003; 53: 291-8.

Tian ZQ, Liu Y, Zhang D, Wang Z, Dong SD, Carreras CW, Zhou Y, Rastelli G, Santi DV, Myles DC. Synthesis and biological activities of novel 17-aminogeldanamycin derivatives. Bioorg Med Chem, 2004; 12:5317-29.

Wang C, Liu P, Luo J, Ding H, Gao Y, Sun L, Luo F, Liu X, He $\mathrm{H}$. Geldanamycin reduces acute respiratory distress syndrome and promotes the survival of mice infected with the highly virulent $\mathrm{H} 5 \mathrm{~N} 1$ influenza virus. Front Cell Infect Microbiol, 2017; 15:267.
Waxman L, Whitney M, Pollok BA, Kuo LC, Darke PL. Host cell factor requirement for hepatitis $\mathrm{C}$ virus enzyme maturation. Proc Natl Acad Sci USA, 2001; 98:13931-5.

Wrona IE, Gozman A, Taldone T, Chiosis G, Panek JS. Synthesis of reblastatin, autolytimycin, non-benzoquinone analogues: potent inhibitors of heat shock protein 90. J Org Chem, 2010; 75:2820-35.

\section{How to cite this article:}

Taechowisan T, Samsawat T, Puckdee W, Phutdhawong WS. Antiviral activity of geldanamycin and its derivatives against influenza virus. J Appl Pharm Sci, 2020; 10(04):113-120. 